\title{
Introduction to the Issue
}

\author{
Eveline Washul, Columbia University
}

I $\mathrm{t}$ is with great pleasure that I write for the inaugural issue of Waxing Moon. Waxing Moon, as its name so poetically illustrates, marks the coming into its own of a new direction of Tibetan studies scholarship. This new direction is one that takes steps toward the challenge of engaging the Tibetan studies community in "genuine dialogue" in spite of differences in native language, disciplinary training, or socio-political histories (Jacoby 2019). In her keynote address to the $14^{\text {th }}$ International Association of Tibetan Studies Seminar in 2016, Sarah Jacoby raised a series of questions that pressed the international Tibetan studies community to consider who we engage with in dialogue and what our motivations are for doing so. She challenged us to push beyond our typical "monologue disguised as dialogue" (Buber, as cited in Jacoby 2019), in which we seek out those who are familiar and similar, and to engage in "genuine dialogue" that establishes active, mutual relations with those whom we may not otherwise easily interface due to linguistic, disciplinary, geographic, social, or other differences (Jacoby 2019).

Waxing Moon rises to this challenge with its commitment to multilingual publishing. This first issue brings together authors writing in English, Tibetan, and Chinese, from universities and academic institutions in the US, China, and the Tibetan Plateau. It is significant to note that these emerging scholars represent a new generation of Tibetan studies scholars who are fluent not only in multiple languages, but in navigating academic and social networks across Asia, Europe, and North America. Perhaps even more exciting is the fact that these authors reflect the rise of young Tibetan Tibetologists, who dominate the pages of this issue and hopefully future issues to come. Many, if not most, of the scholars represented here have spent time engaging in meaningful ways with their colleagues on both sides of the Pacific and Atlantic. Such engagements have been made possible, in pre-pandemic times, through the relatively open environment of scholarly exchange of the last several years, as well as the improvements in multilingual training of Tibetan studies students in programs in the US as well as China. International study, exchange programs, visiting scholar positions, and international research opportunities have created spaces for emerging and established scholars alike to deepen their engagements with one another through mutual dialogue, immersive studies, sharing resources, and collaborating in formal as well as informal ways. Waxing Moon brings to the fore some of the voices that have emerged from these multilingual, multicultural engagements. 
It is also one of the hopes of the journal to be a platform to continue these exchanges, even in a post-pandemic world.

The contributions in this first issue take us from Tibet's imperial period up to the present day and cover topics as varied as religio-politics, material culture and history, local and clan histories, autobiographical writings, borderland studies, photography, decolonial studies, and contemporary film and literature. A common theme running through many of the research essays in this issue is one that breaks down our modern-day notions of ethnicity, language, and statecraft to see the various cosmopolitan and complex political engagements that characterize earlier historical periods. For instance, Tenzin Yewong Dongchung and Urgyen Gyaltsen each contribute close studies of $17^{\text {th }}$ and $18^{\text {th }}$ century material objects and their associated institutions that reveal the ways in which the Qing extended its influence in Inner Asia and the Ganden Phodrang consolidated its power in western Tibet, respectively. Meanwhile, Marnyi Gyatso and Drolma Choekyi examine local histories of regional powers that shed light on the lesser understood aspects of how secular and religious authorities negotiated their relations to lay claim to people and places in Amdo and Kham. Yungdrung Gyurme discusses an autobiography of Surkhang Sichö Tseten that has recently come to light in Amdo Trika, which highlights the dynamic relations between Tibetan, Chinese, and Muslim religious and political figures of $18^{\text {th }}$ and $19^{\text {th }}$ century Lhasa. Finally, Pema Dhondrup in his essay traces how royal clan and family names in the Tibetan Empire evolved from names of individual tsho ba. Each of these studies complicates our understandings of how power was negotiated and exercised between various secular and religious centers of authority from imperial metropole to the Ganden Potrang hegemony to the Sino-Tibetan borderlands.

Other contributions in this issue include Xiaobai Hu's review of the recent publication Frontier Tibet, which collates the results of an important multi-year, international project studying the Sino-Tibetan Kham borderlands. Victoria Liu's review of a photographic exhibition from the National Art Museum of China introduces an Englishreading audience to Chinese photographers documenting eastern Tibet in the 1930s and 1940s and provides a thoughtful analysis of their works. Liu also contributes an interview with Lhasa-based contemporary artist, photographer, and entrepreneur, Nyema Droma, whose work provokes questions of self-representation, culture, and Tibetan manifestations of globalization and is featured on the cover of this issue. Contemporary Tibetan film is also represented in this issue with Palden Gyal's insightful review of filmmaker Sonthar Gyal's recent film, Ala Changso (2018). The conference report makes accessible to a broader audience the proceedings of a roundtable session on decolonial approaches to Tibetan/Buddhist Studies from 
the 2019 meeting of the American Association of Religious Studies. Such a topic could not come at a more apt moment and provokes our field to think deeply about our own embedded practices that might perpetuate structural inequities and how to take steps to redress them. The issue closes with an example of its dedication to multilingual publishing: two pieces of Tibetan contemporary literature written by two prominent Tibetan writers, Tsering Dondrub and Pema Bhum, translated into English by Christopher Peacock and Tenzin Dickie, respectively.

Waxing Moon, with its focus on interdisciplinary and transregional engagement and dialogue, is a welcome addition to the at-present small number of journals dedicated to Tibetan studies and will broaden the scope of scholarship represented in the field. With such diverse offerings found within this first issue, Waxing Moon now challenges readers to step outside our typical zones of comfort and interest and engage in meaningful "genuine dialogue" with topics, scholars, and languages we may not otherwise easily encounter.

\section{Works Cited}

Sarah H. Jacoby, "Tibetan Studies and the Art of Dialogue", Revue d'Etudes Tibétaines, no. 48, April 2019, pp. 152-169. 